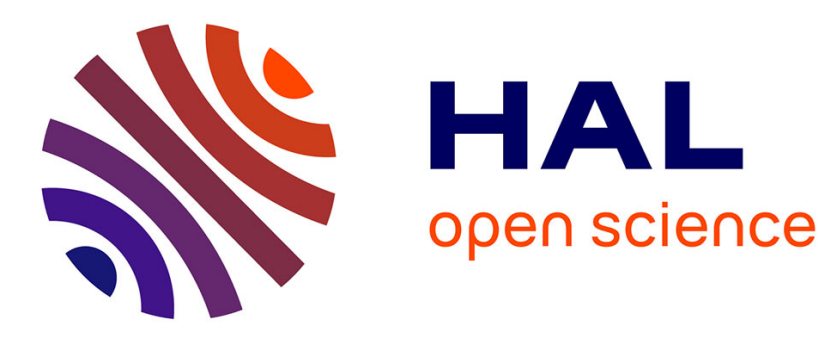

\title{
ECEC2017: The Workshop on E-Commerce and Entertainment Computing
}

\author{
Mitsuru Nakazawa, Masahumi Muta, Kazuki Ookawara, Soh Masuko
}

\section{To cite this version:}

Mitsuru Nakazawa, Masahumi Muta, Kazuki Ookawara, Soh Masuko. ECEC2017: The Workshop on E-Commerce and Entertainment Computing. 16th International Conference on Entertainment Computing (ICEC), Sep 2017, Tsukuba City, Japan. pp.502-506, 10.1007/978-3-319-66715-7_72 . hal-01771278

\section{HAL Id: hal-01771278 \\ https://hal.inria.fr/hal-01771278}

Submitted on 19 Apr 2018

HAL is a multi-disciplinary open access archive for the deposit and dissemination of scientific research documents, whether they are published or not. The documents may come from teaching and research institutions in France or abroad, or from public or private research centers.
L'archive ouverte pluridisciplinaire HAL, est destinée au dépôt et à la diffusion de documents scientifiques de niveau recherche, publiés ou non, émanant des établissements d'enseignement et de recherche français ou étrangers, des laboratoires publics ou privés. 


\title{
ECEC2017: The Workshop on E-Commerce and Entertainment Computing
}

\author{
Mitsuru Nakazawa ${ }^{1}$, Masahumi Muta $^{1}$, Kazuki Ookawara $^{2}$, and Soh Masuko ${ }^{1}$ \\ 1 Rakuten Institute of Technology, Rakuten, Inc. \\ 2 University of Tsukuba \\ \{mitsuru.nakazawa, masafumi.muta, so.masuko\}@rakuten.com \\ okawara.kazuki@entcomp.esys.tsukuba.ac.jp
}

\begin{abstract}
Online e-commerce has been growing continuously. According to eMarketers latest forecasts, worldwide retail e-commerce sales will reach $\$ 4$ trillion USD by 2020 . In addition, using cutting-edge technologies such as augmented reality (AR), virtual reality (VR), mixed reality (MR), sensing technology, image processing, robotics and online payment technology, new shopping experiences that enhance offline or online shopping, or integrate the two types of shopping experiences are being introduced. In this workshop, new concepts and recent progress in shopping experiences are discussed from various perspectives. The workshop will include invited talk sessions by world-leading innovators, and interactive poster and demonstration presentations of submitted papers and abstracts.
\end{abstract}

Keywords: E-Commerce, Entertainment Computing, Workshop

\section{Introduction}

Before the emergence of the Internet, shopping was limited to brick-and-mortar stores, where consumers went to see, touch and purchase physical items (offline shopping). However, after the Internet emerged, it became possible for consumers to engage in a new shopping experience, i.e., online shopping. Online shopping has profoundly changed how we purchase goods. Now we can view and purchase products from a large number of online stores anytime from anywhere. According to eMarketers latest forecasts [1], worldwide retail e-commerce sales will reach \$4 trillion USD by 2020 .

Recently, many cutting-edge technologies such as augmented reality (AR), virtual reality (VR), mixed reality (MR), sensing technology, image processing, robotics and online payment technology have been rapidly refined. Using these technologies, novel services that enhance conventional offline or online shopping have been introduced, e.g., robot reception in a store [2] and AR furniture shopping [3,4]. Moreover, for better coordination of the two types of shopping experiences, there have been some attempts to encourage online shopping in an offline store and vice versa, i.e., Offline-to-Online and Online-to-Offline (O2O). In the near future, it is expected that consumers will not be conscious of the difference of the two, which look like smoothly integrated [5]. 

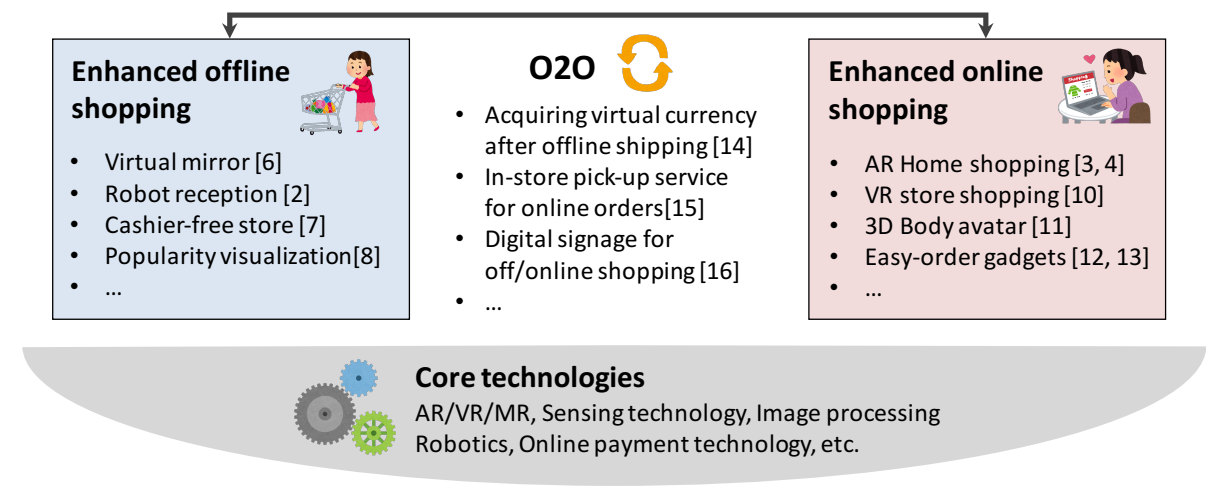

Fig. 1. Overview of enhanced offline and online shopping, and $\mathrm{O} 2 \mathrm{O}$ services

\section{Related work}

In this section, we introduce related work of enhanced offline and online shopping, and $\mathrm{O} 2 \mathrm{O}$ services. Figure 1 represents the overview of related work.

\subsection{Enhanced offline shopping}

To make offline shopping more convenient or entertaining, various attempts have been made in an physical store by using cutting-edge technologies. In a fashion store, a virtual mirror was installed by using AR technology so that a customer can try on as many items as they want without putting off their clothes [6]. In an electronics retail store, intelligent movable robots were assigned to eliminate the shortage of professional explainers who have much knowledge of its products [2]. In a grocery store, [7] proposed a cashier-free system by making the best use of vision sensing and pattern recognition technology to realize a store with no lines and no check out. In a sales event of a department store, to easily understand the popularity of each event store, 3D-animated human-shaped icons appeared on a paper map representation in a large display monitor based on hourly point of sales (PoS) data [8]. Purchasing behavior data such as PoS data and a customer flow map are valuable for not only customers but also retailers who hope to optimize their store layout [9].

\subsection{Enhanced online shopping}

Although even conventional online shopping is convenient in term of anytime anywhere shopping, it is originally less sense of reality because an intangible product is displayed in not actual size on a $2 \mathrm{D}$ web browser. To solve such lack of reality, AR technology has been often employed. For example, [3, 4] proposed an AR home shopping experience where actual size furniture appears on a smartphone display. VR technology, which allows a user to secure a higher immersion 
feeling, is another approach to put more reality in online shopping. [10] developed a VR showroom that enables a user to dive into a virtual store that looks exactly like a physical one. In online clothes shopping, technology of 3D body shape estimation can be also utilized. To determine if an article of clothing suits customer's body or not on a website, [11] displayed a clothing 3D model with a representative 3D body shape, which is generated from body shape estimation using anatomical information (e.g., height and weight).

Another enhancement of online shopping is to save customer's trouble in ordering goods. Recently, some Internet-of-things gadgets that allow an user to order goods by voice recognition [12] or just pushing a button [13] have been released.

\section{$2.3 \quad$ O2O services}

To draw potential customers from offline to online shopping or vice versa, some $\mathrm{O} 2 \mathrm{O}$ services have been launched. For examples, [15] started in-store pick-up service for online orders. In [14], an user got rewarded with virtual currency that can be used in online shopping after offline shopping. [16] released a digital signage display that can order goods on-line in case of that they are sold out in the physical store.

\section{Overview of ECEC2017}

Although many services beyond conventional offline and online shopping have already been proposed as described in Section 2, we believe that shopping experiences will keep evolving based on upcoming new technologies. Therefore, to discuss new concepts and current progress in shopping experiences, we will hold this workshop. It will include invited talk sessions and an interactive poster and demonstration session. In the invited talk sessions, world-leading innovators will give a talk about their specialized fields of VR shopping [17], Retail analysis [9], Image processing for e-commerce [18] and Drone business [19]. The interactive poster and demonstration session will cover the following topics:

- Gamification of shopping experiences

- Entertainment psychology and shopping experiences

- Shopping attractions

- Online-to-offline, Omni channel with entertainment

- Use of wearable/smart devices for shopping

- Physical shopping interfaces

- Augmenting real-world shopping experiences using VR/AR/MR technologies

- Image/Video processing for e-commerce

- Best practices in e-commerce and entertainment

We look forward to discussion with you toward future shopping at ECEC2017. 


\section{References}

1. eMarketer, "Worldwide Retail Ecommerce Sales Will Reach $\$ 1.915$ Trillion This Year," https://www.emarketer.com/Article/ Worldwide-Retail-Ecommerce-Sales-Will-Reach-1915-Trillion-This-Year/ 1014369, Accessed on 2017/06/19

2. Nestle, "Nestle to use humanoid robot to sell Nescafe in Japan," http:// www.nestle.com/media/news/nestle-humanoid-robot-nescafe-japan, Accessed on $2017 / 06 / 19$

3. CNET, "iPhone's futuristic AR dream starts with Ikea," https://www.cnet.com/ news/ikea-ar-app-apple-arkit-report/, Accessed on 2017/06/19

4. S. Murakami, T. Mukasa and T. Tung, "Mobile Virtual Interior Stylization from Scale Estimation," ACM SIGGRAPH 2016 Posters, pp. 14:1-14:2, 2016

5. U. Bandara and J. Chen, "Ubira: A Mobile Platform for an Integrated Online/Offline Shopping Experience," Proceedings of the 13th International Conference on Ubiquitous Computing (UbiComp2011), pp. 547-548, 2011

6. Fitnect, "3D Virtual fitting dressing room / mirror," http://www.fitnect.hu/, Accessed on 2017/06/19

7. Amazon, "Amazon Go," https://www.amazon.com/b?node=16008589011, Accessed on $2017 / 06 / 19$

8. S. Masuko and R. Kuroki, "AR-HITOKE: Visualizing Popularity of Brick and Mortar Shops to Support Purchase Decisions," Proceedings of the 6th Augmented Human International Conference (AH2015), pp. 185-186, 2015

9. ABEJA, "ABEJA PLATFORM for Retail," https://service.abeja.asia/, Accessed on $2017 / 06 / 19$

10. Trillenium, "Trillenium VR showroom," http://www.trillenium.com/ vr-showroom.html, Accessed on 2017/06/19

11. Fits.me, "Fits.me," https://fits.me/, Accessed on 2017/06/19

12. Google, "Start shopping with the Google Assistant on Google Home," https://blog.google/products/home/ start-shopping-google-assistant-google-home/, Accessed on 2017/06/19

13. Amazon, "Amazon Dash Button," https://www.amazon.com/Dash-Buttons/b? node $=10667898011$, Accessed on 2017/06/19

14. Rakuten, "McDonalds and Rakuten Announce Rakuten Point Card Partnership to Improve Customer Convenience," https://global.rakuten.com/corp/news/ press/2017/0526_01.html, Accessed on 2017/06/19

15. Rakuten, "Rakuten and Lawson to Collaborate to Launch Convenience Store Pickup Service," https://global.rakuten.com/corp/news/press/2015/0825_01. html, Accessed on 2017/06/19

16. Digital Signage Today, "Interactive Kiosks Draw in O2O Sales for Department Stores," https://www.digitalsignagetoday.com/press-releases/ interactive-kiosks-draw-in-o2o-sales-for-department-stores/, Accessed on $2017 / 06 / 19$

17. Rakuten.today, "Getting Real About VR in e-commerce: Rakuten Virtual Boutique," https://rakuten.today/blog/vr-e-commerce-virtual-boutique.html, Accessed on 2017/06/19

18. E. Simo-Serra, "Research", http://hi.cs.waseda.ac.jp/ esimo/en/research/, Accessed on 2017/06/19

19. Rakuten, "SoraRaku: Drone Delivery," https://soraraku.rakuten.co.jp/en/, Accessed on 2017/06/19 